\title{
Jane: A Screenplay on the Importance of Letting Go of Stigma Towards Mental Illness
}

\author{
Godwin, Andhika Pratama \\ English Department, Faculty of Letters, Petra Christian University, Siwalan Kerto 121-131, Surabaya, 60236, \\ East Java, INDONESIA \\ e-mail: andhikagodwin.info@gmail.com
}

\begin{abstract}
Many people with mental illness face the double challenges. Not only do they struggle with the symptoms of their illness, they also struggle with the stigma that the society has towards their illness. Through this creative project, I would like to discuss how stigma towards mental illness affects those who suffer from it negatively, and how letting go of stigma benefits those who are mentally ill and those who are not. I use Erving Goffman's theory on social stigma, and another theory regarding self-stigma by Patrick W. Corrigan and Deepa Rao. These theories helped me understand how a stigma can be internalized by people with mental illness, and how it further worsens their symptoms. Moreover, the theories helped me create my story and my characters as realistically as possible and suggest a plausible solution for the problem through my story. My project is in the form of a romance drama short film screenplay. It tells the story of Jae-in Kim, a counselor in a suicide hotline, who is falling for a guy named Jon-young Park. They have been talking on Facebook for months, and when they are about to meet for the first time, she suddenly finds some similarities between him and a depressed guy who often makes suicidal calls to the hotline. It makes her reluctant to build a deeper relationship with him, which becomes a barrier for their relationship, and also challenges her perceptions towards people with mental illness. At the end, when she finally lets go of her stigma, their relationship gets better, and she becomes more inspired to help the mentally ill through her job.
\end{abstract}

Keywords: Romance drama, social stigma, self-stigma, mental illness, suicide hotline

\section{INTRODUCTION}

My story takes place in South Korea, a country in which "Jane" is relevant to be told due to the fact that for the past several years, the country has had one of the highest suicide rates among the OECD (The Organization for Economic Co-operation and Development) countries. In 2011, the Korean National Statistic Service reported that 15,906 people committed suicide in a year. That is about 1000 people taking their lives every month -43 people every day or one person every 34 minutes (Vice, 2016). High suicide rates have become quite a huge phenomenon in South Korea ever since the country's rapid economy rise in the 1980s. Having experienced such a rapid growth in economy, the situation put a huge pressure on the people to work hard and be successful in this hugely competitive and individualistic society. Many people who are pressured and troubled by this situation have decided to take their own lives in order to escape their problems (Dhawan, 2015). To provide a solution for this problem, the South Korean government has put some efforts to prevent suicide such as campaigns to raise awareness towards this problem, involving social workers to keep watch for suicidal behaviors at famous suicide spots, and also suicide hotlines (Cain, 2014).

Nevertheless, it is important to acknowledge that even though South Korea has had a high suicide rate for several years, it is a matter of fact that suicides happen in other parts of the world as well. Either a country is developed or not, it is undeniable that problems happen everywhere. Also depending on how a culture views a problem, people find escape from their problems differently, one of which is by committing suicide. Even though suicide is regarded as a sin by many countries, some countries do not. 
Japan is one of the countries that do not view suicide as a sin. The feudal Japanese culture regards suicide as a way to preserve one's family honor. Suicide has been regarded by the Japanese as an honorable way of making amends for public disgrace and to express one's deep sense of shame ever since the samurai era. This point of view is very different from the West, where suicide is viewed as a sin by religions like Christianity (Louie, 2014).

Many countries, including South Korea, have made some efforts to prevent people from taking their lives. For instance, suicide hotlines are also available in countries such as United States and Australia. Not only in developed countries, many efforts to prevent suicide are also available in undeveloped countries. For example, there are Friendship Benches available everywhere in Zimbabwe where people can talk with elderly health workers about their problems. Whereas suicide and depression are still considered taboos in Zimbabwe, patients with depression are more than 3 times less likely to have symptoms of depression after 6 sessions with the Friendship Bench according to Journal of the American Medical Association (Singh, 2017). These are the facts that I want to acknowledge and use for my film. Even though my film takes place in South Korea, I believe that the message and the purpose that I aim to deliver can also be shared universally. Because as human beings, I believe that all of us share the same feelings about this problem, either as the ones that deal with depression and consider suicide or those who lost the ones that they care about to suicide.

The topic of my film deals with mental illness and the stigma that surrounds it in our society. Mental illness refers to mental health conditions that affect the mood, the thinking, and the behaviorsdisorders that make people feel miserable and affect their ability to function in daily life. Examples of mental illness include depression, anxiety disorders, schizophrenia, eating disorders, and addictive behaviors (Mayo Clinic Staff, 2015). Many people with serious mental illness face the double challenge. Not only do they struggle with the symptoms that come from their disease, people with mental illness are also challenged by the stereotypes and prejudice that come from the misconceptions about their disease in the society. Consequently, people with mental illness are robbed of the opportunities that define a quality life. For instance, people with mental illness may find difficulties in getting good jobs, safe housing, and also in building relationships with a diverse group of people (Corrigan \& Watson, 2002).

These types of discrimination that come from other people can become internalized, which leads to the development of self-stigma of which people with mental illness begin to believe the negative thoughts expressed by others to them and think of those thoughts as who they are. In result, this self stigma can cause them to feel shame, low self-esteem, and unwillingness to try and seek help to recover (Corrigan, Druss, \& Perlick, 2014). All these facts about mental illness and the stigma that surrounds it inspired me to write a story that talks about it. These situations inspired me to tell a story that introduces the notion of the stigma and how important it is to fight it and let it go, because I believe that to let go of the stigma is to encourage those who suffer from mental illness to seek help that is necessary for their recovery.

I chose the form of a short film screenplay to tell this story because I have always loved films for their ability to tell stories and move people's hearts with so many things beyond pictures such as dialogues, acting, sound effects, and music. Films can be a source of entertainment for everyone; however, the impacts of films can also be something that is way beyond entertaining. Films can educate people; it can open our hearts to so many things that are going on in the world no matter how big or small, social or personal. Another reason for me to love films is also because film has always been one of my biggest outlets for expressing what I feel and think.

As for genre, "Jane" is a drama film with the subgenre of romance. Romantic drama film is a genre that explores the complex side of love, focusing on an obstacle that is preventing love between two people (Buffam, 2016). In my film, the romantic subgenre is centered on how Jae-in and Jon-young struggle to meet after months of falling for each other. Furthermore, by choosing romance as the subgenre, I believe that I can deliver a more hopeful attitude about the problem of stigmatizing the mentally ill in my story by romanticizing it. Nowadays, it is a fact that many people are still reluctant to build a relationship with people suffering from mental illness due to the stigma that they have towards 
the mentally ill. A research published in the Journal of Health and Social Behavior (Vol. 41, No. 2) finds that 68 percent of Americans do not want a person with mental illness marrying into their family (Dingfelder, 2009). In this case, I intended to romanticize Jae-in and Jon-young's relationship to show that the reality of stigmatizing people with mental illness can change - that the fear of having a relationship with the mentally ill could be wrong.

In my project, I would like to explore the fact that many people stigmatize mental illness, and how it negatively affects people who suffer from it. Also, I would like to explore how letting go of stigma towards mental illness helps individuals who suffer from it and also leads to a better understanding about the illness. After discussing the reality of stigma towards mental illness and its effects, in the context of my film, these are the things that I would like to explore: how Jae-in stigmatizes mental illness, how Jaein's stigma towards mental illness negatively affects Jon-young and their relationship, and how Jae-in's letting go of her stigma towards mental illness helps Jon-young as a person suffering from mental illness, and how it benefits her as well.

The first theory that I used for this creative work is the theory of social stigma by Erving Goffman. In his book Stigma: Notes on the Management of Spoiled Identity (1963), Erving Goffman refers to stigma as an attribute that deeply discredits a person from his society. It begins when a society establishes some terms to categorize people and the complement of attributes felt to be ordinary and natural for members of each of these categories - categories of people that are likely encountered to be there. These categories, furthermore, allow us to deal with anticipated others without any special attention or thought. Moreover, when the society encounters a person that does not fit into these categories, it will furthermore lead to stigma towards him (Goffman, 1963).

In my story, my character Jae-in Kim still carries some sort of stigma and prejudice towards people with mental illness even though she works as a counselor in a suicide hotline and deals with suicidal people every day as her job. However, Jae-in does not fully stigmatize the mentally ill such as thinking and promoting the thought that they are dangerous. Instead, she has some negative assumptions towards them because she does not truly understand mental illness and people who suffer from it, in the sense that she has never had any personal or intimate relationship with them before; therefore, it makes her doubtful with the idea of having a relationship with Jon-young who suffers from mental illness. This stigma arises in herself as she realizes that Jon-young may be the suicidal guy who often calls the hotline, assuming that he may not be the right guy for her after all, and that he is only using her as something that distracts him from his illness. As in Goffman's theory, Jae-in's negative assumptions towards Jonyoung reduces his persona in her mind, from a whole and mysterious person into a troubled guy with a lot of life baggage.

Goffman also suggests the idea that the experience of stigma can be different depending on the stigma's concealability. There are two kinds of attributes in this context regarding concealability: one is the discredited and the other is discreditable. The discredited attribute refers to an attribute that is known about and evident, whereas the discreditable refers to passable and distinguishable attributes. According to Goffman, there are grossly three types of stigma in our society. The first type of stigma refers to physical deformities of an individual, which concerns the abominations of the body. The second type of stigma refers to blemishes of individual character. This type of stigma is usually used to refer to people who have had known record of mental disorder, suicidal attempts, homosexuality, and addiction problems. The third type of stigma refers to tribal attributes of a person, which concerns his race, nation, and religion (Ibid).

My character, Jon-young Park, is experiencing the second type of stigma, which refers to blemishes of individual character. Particularly, Jon-young Park is suffering from Bipolar disorder, which is also known as manic depression. It is a mental condition that causes serious shifts in mood, energy, behavior, and thinking. It takes its sufferers to feel the highs of mania on one extreme and then to the lows of depression on the other. The mood changes of bipolar disorder can be so intense that they interfere with the ability to function (Smith \& Segal, 2016). My character Jon-young has also had some thoughts of suicide, which in a great deal, is influenced by the memory of his mother killing herself. Suicide is a major risk factor in the very severe depressive phase of bipolar disorder. The risk of suicide 
is even higher for sufferers who have frequent depressive episodes, mixed episodes, or a family history of suicide (Ibid).

The second theory that I used for my project is the theory of self-stigma by Patrick W. Corrigan and Deepa Rao, referencing to their article titled On the Self-Stigma of Mental Illness: Stages, Disclosure, and Strategies for Change which was published in Can J Psychiatry (The Canadian Journal of Psychiatry) in 2012. In their article, Patrick W. Corrigan and Deepa Rao define fully the concept of selfstigma, its negative effects, and also suggest some ways to reduce it.

Social psychologists study stigma as something that is related to internal and behavioral processes that lead to social isolation and ostracism. They also acknowledge the role of societal and interpersonal processes in the creation of stigma in society. Negative stereotypes have long been associated with mental illness. Negative stereotypes regarding mental illness can be harmful to its sufferers, as aggreing and believing in them lead to the development of negative feelings and emotional reactions (prejudice) in the society. For example, people who believe that schizophrenia is dangerous can suggest and promote the idea that mental illness is dangerous to other members of the society. Consequently, these negative reactions will lead to discrimination towards the mentally ill, further isolating them due to the negative stereotypes and the prejudice that they are dangerous (Ibid).

People with mental illness are vulnerable to these negative stereotypes in the sense that they can also believe and endorse these stereotypes about themselves. The thought of them being dangerous in the society can also develop within the mentally ill, leading them to the belief that they are indeed dangerous. This phenomenon is called self-stigma, which further worsens the cause of their illness as it diminishes feelings of self-worth and hope. Self-stigma is also associated to the "why try" effect, which poses as a barrier in achieving life goals. For example, people with mental illness will not even bother to seek the help that they need as they already believe that they are dangerous and incureable (Ibid).

In their article, Corrigan and Rao also examined and suggested some ways to challenge selfstigma. They suggested that empowerment might be an antidote to self-stigma, as it encourages the mentally ill to achieve life goals and lessens negative consequences of the stigma. Empowerment involves power, control, activism, optimism, and is also associated with high self-esteem and increased social support such as help programs. They also suggested that one way to counter the shame of stigma is to "come out of the closet" - to let other people know about one's psychiatric history. Research has interestingly shown that coming out with mental illness is associated with decreased negative effects of self-stigmatization on quality of life. Being open about one's struggle with mental illness leads to less worry and concern over secrecy, and having other people know about the illness can also help the mentally ill to find support from family and peers. They may also find that being open about their illness promotes a sense of power and control over their lives (Ibid).

They also suggested that peer support such as consumer-operated programs provide another way for the mentally ill to enhance their sense of empowerment. Recently, consumer-operated programs have developed, including housing programs, homeless services, anti-stigma services, technical services, crisis reponse programs, and employment programs. Groups like these provide a range of support services and promote a sense of community from shared experiences for people with mental illness. Research has shown that participants reported improvements in self-reliance and independece - coping skills and knowledge and feelings of empowerment (Ibid).

My character Jon-young also suffers from this type of self-stigma in the sense that he believes the idea of himself being worthless and fearing that everybody will leave him alone. This sense of worthlessness developed from his childhood and his broken family, the idea of his father abandoning him, and the memory of his mother telling him that he is worthless.

In attempt to counter these negative feelings and protect himself from the stigma, Jon-young chooses to hide his problems from the public. In effect of hiding, he often feels self-conscious and continuously worried and afraid that other people will find out about his problems and stigmatize him. However, Jon-young is also a man who wants to change himself for the better and recover. Therefore, he chooses to talk about his problems and come out in a place and condition where he feels safe and 
private. He does this by continuously calling the suicide hotline (technical services $\&$ crisis reponse programs) and talking to a counselor on the phone.

\section{OUTLINE OF THE CREATIVE WORK}

My creative work is in the form of a short film screenplay with the duration of 18 minutes.

\subsubsection{Theme}

Many people are reluctant to have a relationship with those who suffer from mental illness due to the stigma surrounding them in the society. Therefore, the first theme that I aim to deliver from my film is that letting go of stigma towards mental illness leads to building a better relationship between people who suffer from mental illness and those who do not. In my story, this is also what happens to Jae-in and Jon-young's relationship as Jae-in starts to let go of the stigma that she has. Their relationship becomes close again, and a new possibility of their relationship becoming more intimate arises after Jaein decided to let go of her stigma. As for Jae-in who works as a counselor in a suicide hotline, letting go of her stigma also benefits her in the sense that it makes her feel freer and more inspired to help individuals suffering from mental illness.

The second theme concerns the negative effects that stigma towards mental illness brings and the importance of letting that stigma go, encouraging the mentally ill to seek the help that they need. I aim to show this theme from Jae-in's reaction when she finds out that Jon-young is actually the depressed and suicidal guy who often calls the suicide hotline where she works. Even though Jae-in works as a counselor in a suicide hotline, she still carries some stigma towards the mentally ill. Jae-in may still stigmatize the mentally ill due to her lack of deep understanding about people with mental illness, and also because her job in dealing with the mentally ill often makes her tired.

\subsubsection{Plot}

\subsubsection{Pitch}

a) Jae-in is tired after her work at the suicide hotline; however, she feels better and bursting with excitement after Jon-young asks her to meet him for the first time.

b) One day before meeting him, Jae-in learns about the strong similarities between him and a depressed man who always calls to the suicide hotline, which makes her doubtful and unsure about meeting him.

c) After it is ultimately confirmed that the depressed man is Jon-young and he cries about Jae-in leaving him, Jae-in is reminded about why she fell for him in the first place and she lets go of her expectations and ideas about him.

\subsubsection{Synopsis}

Jae-in, a counselor in a suicide hotline, is falling for Jon-young, a guy whom she met online. They have been talking to each other for some time but have not met yet. She has been so excited about finally meeting him after months of chatting; however, she suddenly finds some strong similarities between Jon-young and a depressed man who always calls to the suicide hotline to cry about his life.

After learning the similarities between Jon-young and him, Jae-in suddenly feels doubtful and unsure about meeting him. She abruptly cancels their meeting without even telling him. That night at work, she receives a call from the depressed man. After some time talking to him, it is ultimately confirmed that he is indeed Jon-young and that he is thinking about ending his life after Jae-in, the woman who was his only hope, abandoned him.

Jae-in is suddenly filled with mixed-up feelings. She is sad, confused, and guilty, but she has to be professional now in order to stop him from killing himself. Jae-in does not tell him who she really is, but she tells him to try remembering why he was holding on to her in the first place. From hearing his reasons, Jae-in is taken aback. She is also reminded why she fell for him in the first place. In the end, Jon-young feels better and he promises to try again. Jae-in has succeeded. They hang up the call and then she cries, feeling relieved from the tension and starting to accept her fate and who Jon-young really is. 
Days after that, everything seems to have gotten better. Jae-in is walking on the street, and constantly smiling at her phone after receiving a text from someone. She then crosses the road, and suddenly bumps into Jon-young who is so focused on texting on his phone. Jon-young quickly apologizes and walks away, not realizing who he has just bumped into. Jae-in looks at him from afar. She is stunned and confused, but then she turns around and walks away. She's constantly smiling as she looks forward to see what the future holds.

\subsubsection{Characterization JAE-IN KIM}

Age $\quad: 27$ years old

Occupation : Counselor in a suicide hotline

Jae-in Kim has been working as a counselor in a suicide hotline for 3 years, having always been interested in helping other people. Even though she found her job difficult, she was happy with her boyfriend and was about to get married after 2 years of dating. However, everything changed when her boyfriend suddenly abandoned her for another woman. It left her feeling depressed for quite a long time; however, she slowly recovered due to the support of her loving family and close friends. After these depressing moments, Jae-in built up her guard and promised to herself that she would never let a guy dump her so easily ever again.

Times passed, and she met a guy named Jon-young Park on Facebook. They have been talking to each other for months, and eventually discovered that they had the same interests. From then on, things started to get more intimate between them. Jae-in started to fall for him because he resembled her ex in some ways. Amongst all things, she fell for Jon-young because he filled the empty space in her life. However, she knows that she should not let her guard down easily because she is afraid of being hurt anymore. Therefore, she made him promise that they would only talk to each other on Facebook for 3 months, and that they would only meet if it continues and nothing bad happens.

\section{JON-YOUNG PARK}

\section{Age $\quad: 27$ years old \\ Occupation : Freelance writer}

Jon-young Park is the only son in his family. His parents got married because his mother suddenly got pregnant with him in the middle of their short relationship. Their marriage was arranged by their families in order to protect their image. Even though they loved each other in the beginning, their marriage was always perceived negatively by other people because Jon-young's mother did not come from an upper class family like his father. People would call their marriage a business scam planned by Jon-young's mother, saying that she deliberately caused the pregnancy to move up her social status. Although that was actually not true, all of those rumors eventually broke apart their marriage.

Their marriage turned bitter. They constantly fought with each other to the point where Jonyoung's father could not take it anymore. He eventually left home but did not get a divorce. Through all of these events, Jon-young was only a young teenager. The situation at home was depressing for him. He would constantly stay away from home, burying himself in his studies and working overtime. What made things even worse for him is that his mother would often drunkenly tell him that he was the cause of all the problems, which she would continuously do when she was feeling desperate until the day she killed herself. The memory of his mother killing herself would sometimes come back and haunt him, making him scared and anxious that he will end up like her in the end.

Now a 27-year-old man, Jon-young is continuously feeling worthless and depressed. However, he keeps trying to tell himself that he is not worthless. After everything that he has gone through, he still managed to continue living through his writing, which served him an escape from the reality. Jon-young still has the will to overcome the darkness in his life. He also has a small hope in his heart to turn things around, which he gets from getting in contact with Jae-in. Even though the past would come back to him at times, he gets a sense of comfort and hope when he's texting her. The thrill and excitement of finally meeting her in the future are the things that get him through his dark days now. 


\subsubsection{Settings}

South Korea

My story takes place in South Korea with Korean characters. Specifically, these are the settings in which my story takes place:

\section{The office of the suicide hotline}

There are two scenes that occur in the office of the suicide hotline in my film. The scenes in the hotline office have bluish color tone to show and intensify the pressure of working there.

\section{Jae-in's apartment}

Many events in my film also occur in Jae-in's apartment. For the apartment scenes, the events take place inside her living room, her bedroom, and also her bathroom. The apartment scenes are also dimly lit in order to show Jae-in's dull and lonely life.

\section{Street/Crossroad}

The scene at the crossroad on a street occurs in the last scene of the film where Jae-in and Jonyoung unexpectedly bump into each other. My intention in making the ending scene happen outdoors on a street is to give a feeling of relief to my audience after only seeing enclosed settings throughout the film. This outdoor scene is also to represent Jae-in's newly open state of mind after letting go of her stigma towards Jon-young whom suffers from mental illness.

\section{Beach}

The beach scenes occur only in Jae-in's imagination. Both of the beach scenes in my film are bright in color and lighting in contrast to the other scenes to represent Jae-in's longing for freedom and escape from her dull and lonely life.

\section{Jon-young's apartment}

The scenes in Jon-young's apartment also occur in Jae-in's imagination when Jon-young calls the hotline for the second time in the film. The messy setting and the dark lighting in the apartment partly represent Jae-in's stigma towards people suffering from mental illness as individuals who are very miserable and messed up in life.

\section{CONCLUSION}

\subsection{Concluding Thoughts}

In this section, I am going to explain how I achieve the three purposes that I aim to show through my screenplay. The first purpose, which deals with Jae-in's stigmatizing Jon-young whom suffers from mental illness as a person who cannot have a normal or even a love relationship with other people, is achieved by showing how she suddenly becomes reluctant to meet Jon-young when she finds that he might be the depressed guy who often calls her on the suicide hotline.

The second purpose, which concerns with how Jae-in's stigma towards Jon-young discourages him from his hopes in getting better and becomes a barrier for their relationship, is achieved by showing how Jon-young suddenly feels down and depressed again when Jae-in abruptly cancels their first meeting. Because of this, he feels that Jae-in has abandoned and given up on him before even meeting him. Moreover, this causes his depression and feelings of worthlessness after being abandoned by his family to rise up again and further brings back his suicidal thoughts again.

As for the third purpose, concerning with how Jae-in's letting go of her stigma makes her feel freer and more inspired to help individuals suffering from mental illness and how her positive attitude encourages Jon-young to get better, I have achieved this through the last scene of the film. In the last scene, the situation seems brighter and better than the previous scenes, and Jae-in and Jon-young are making plans again to meet each other for the first time before unexpectedly bumping into each other on the street. This scene shows that good things can happen for Jae-in and Jon-young now that she has let go of her stigma, in the sense that Jon-young survives and did not commit suicide and that they could have a better and closer relationship in the future. By them having a closer relationship in the future, it could empower Jon-young to get better and improve his life and cause Jae-in to feel more inspired to help other people with mental illness. 


\section{REFERENCES}

Buffam, N. (2016). Drama. Retrieved January 10, 2017 from The Script Lab: https://thescriptlab.com/screenplay/genre/drama

Cain, G. (2014, March 16). Why South Koreans are killing themselves in droves. Retrieved January 10, 2017 from Salon: http://www.salon.com/2014/03/15/why_is_suicide_so_popular_in_south_korea_partner/

Corrigan, P. W., Druss, B.G., \& Perlick, D.A. (2014). The impact of mental illness stigma on seeking and participating in mental health care. Psychological Science in the Public Interest, 15(2), 3770. Retrieved from https://www.ncbi.nlm.nih.gov/pubmed/26171956

Corrigan, P. W., \& Rao, D. (2012). On the self-stigma of mental illness: Stages, disclosure, and strategies for change. Can J Psychiatry, 57(8), 464-469. Retrieved from https://www.ncbi.nlm.nih.gov/pmc/articles/PMC3610943/

Corrigan, P. W., Druss, B. G., \& Perlick, D. A. (2002). Understanding the impact of stigma on people with mental illness. World Psychiatry, 1(1), 16-20. Retrieved from https://www.ncbi.nlm.nih.gov/pmc/articles/PMC1489832/

Dhawan, R. K. (2015, December 20). Why Koreans commit suicide. The Korea Times. Retrieved from: http://www.koreatimes.co.kr/www/news/opinon/2016/03/162_193603.html

Dingfelder, S. F. (2009). Stigma: Alive and well. Monitor on Psychology Vol 40, No. 6, 56.

Goffman, E. (1963). Stigma: Notes on the management of spoiled identity. In E. Goffman, Stigma: Notes on the Management of Spoiled Identity (pp. 1-17). Touchstone.

Louie, S. (2014, June 30). Asian honor and suicide. Retrieved February 15, 2017 from Psychology Today: https://www.psychologytoday.com/blog/minority-report/201406/asian-honor-andsuicide

Singh, M. (2017, January 10). The friendship bench can help chase the blues away. Retrieved February 15, 2017 from npr : http://www.npr.org/sections/goatsandsoda/2017/01/10/508588401/thefriendship-bench-can-help-chase-the-blues-away

Staff, M. C. (2015, October 13). Mental illness: Diseases and conditions. Retrieved February 15, 2017 from Mayo Clinic: http://www.mayoclinic.org/diseases-conditions/mentalillness/basics/definition/con-20033813

Vice. (2016, November 15). On patrol with South Korea's suicide rescue team. Retrieved March 15, 2017 from VICE: https://www.vice.com/en_id/article/on-patrol-with-south-koreas-suiciderescue-team-id 